\title{
Matrix Converter Control Strategies and Modulation Techniques
}

\author{
Sh Suresh Kumar Budi, M.Suneel Kumar
}

\begin{abstract}
The matrix converter is an variety of restrained semiconductor changeovers that interfaces straightforwardly to the three-phase (3-Ø) supply to the 3-Ø load. This paper presents the cutting edge see in the improvement of this converter, beginning with a concise recorded survey. A significant piece of this paper is discourse of the most significant modulation and control techniques grew as of late. Uncommon consideration is apt to current contemporary technologies cultivated to take care of commutation issue. certain new varieties of energy bidirectional changeovers associated in a exclusive module and certain pragmatic outcome akin to the feasible appeal of this methods like over voltage safety, accustom of filtrate, and ride-through skill are further presented.

Ultimately, this paper consists of simulation blocks and their corresponding results and also relation between different control techniques. Over the most recent couple of years, an expansion in research achievement obsolete watched, carrying this analysis confining to the modern requisition.
\end{abstract}

Keywords-Voltage Source Inverter(VSI), Space Vector Modulation (SPVM)

\section{INTRODUCTION}

Conventionally, ac voltages and currents possess uncertain magnitude and frequency are produced by PWM regulate VSI (PWM-VSI) can be viewed as indirect power alteration considering the methodology is depends on pair of power alteration via a capacitor (dc link).

An alternative to indirect power alteration is the direct power converter such as a forced-commutated cyclo-converter (FCC) contrarily noted as a matrix converter, has no restriction on yield frequency which uses switches like the IGBT, MOSFET, and MCT.

A four-quadrant fully controlled bidirectional switch is a primary component in a matrix converter, in which high-frequency operation permits. Hence no need of energy storage elements. Be that as it may, the genuine improvement in regard to matrix converters began among the achievement of Venturini and Alesina bring out in 1980 [5]. They exhibited bidirectional power switches and in this way presented the name "matrix converter."

In 1989, Huber et al. bring out the foremost of a progression of documentation where the standards of space-vector modulation (SPVM) were connected to the matrix converter modulation problem [6]. The modulation techniques based on the Venturini access are identified as

Revised Version Manuscript Received on August 19, 2019

SH Suresh Kumar Budi, Assistant professor, CMR Technical Campus, MEDCHAL,Hyderabad, Telangana, India.(email: bsrihari99@gmail.com)

M.Suneel Kumar, Assistant professor, CMR College of Engineering \& Technology, MEDCHAL,Hyderabad, Telangana, India(email: msuneelkumar@cmrcet.org) "direct methods," while such establish on the "fictitious dc link" are identified as "indirect methods.

Today, the research is primarily centered around operational and technological aspects: reliable execution of commutation techniques protection issues execution of bidirectional switches and packaging operation under unusual circumstances; ride-through ability and input filter design. The motivation behind this paper is to give a survey of key angles concerning matrix converter operation and to set up the cutting edge of this innovation.

\section{MATRIX CONVERTER}

A Matrix Converter has 9 bi-directional switches has less size and weight contrasted to controlled rectifier/inverter design in Fig 1.
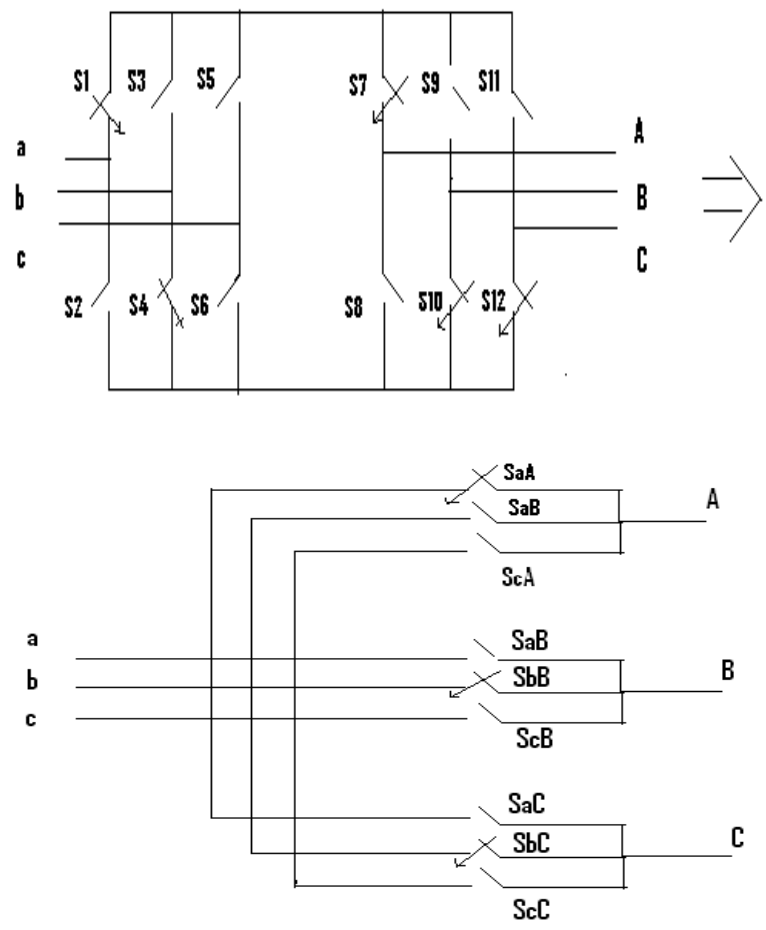

Figure 1. Matrix Converter relation with conventional converter.

The matrix converter needs bidirectional switches equipped of obstruction voltage and acquit current in two paths. Shockingly, here no certain apparatus right now accessible, so IGBT is used in which alone gate driver is necessary for each switch. 


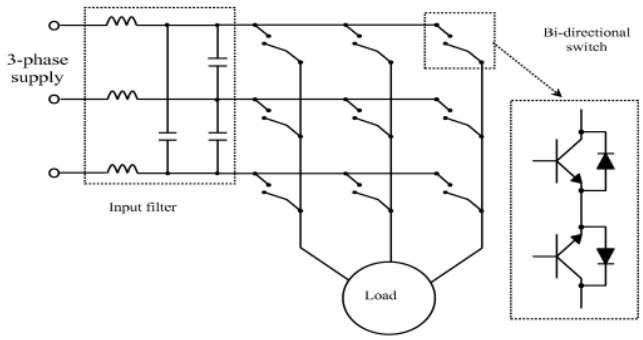

Figure 2. Bidirectional Switch Of Matrix Converter.

The common emitter configuration uses two sets of antiparallel diodes and IGBTs associated to control the bidirectional current flow. By the use of conventional VSIs dependable current commutation among switches in matrix converters is obtained. Due to over currents this intend ensue in short circuit across line-to-line and the obliteration of converter. Additionally, the switches during each output phase shouldn't be turned off by the side of any instant. It will cause reduction of inductive load current, causing large over-voltages. These both reflections cause a divergence since these devices may not switched immediately because of propagation delays and fixed switching times. by timing diagram the delay will be determined.

A few filtrate methods like elementary LC and multistage LC may be examined. It may be appeared that elementary LC filtering, is the best selection because of expenditure and capacity. In a matrix converter, A clamp revolution is the best answer to stay away from over voltages, Ride-through capabability. In which it uses switch-mode power supply. A flux and speed viewer is worn to resume the drive as of nonzero flux and speed conditions in the shortest time.

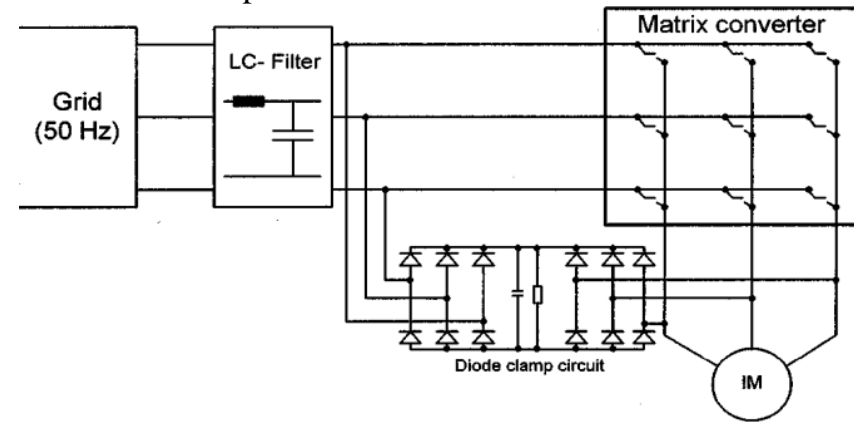

Figure 3. Matrix Converter with LC \& clamping circuit.

\section{Essential Switching}

It is a single-level converter having an size of $m \times n$ bidirectional switches to join phase load, typically a motor. Normally, a voltage source is fed to this converter directly, an $\mathrm{m}$-phase voltage source to an n-phase load. Converter has 3 -phase voltage source to a 3 -phase load i.e., a $3 \times 3$. Defining the switching function of a single switch as

$$
\begin{aligned}
& \text { Skj }=\left\{\begin{array}{l}
1, \text { Switch } S k j \text { closed } \\
0, S \text { witch } S k j \text { open }
\end{array} \text { where } k=\{A B C\} \& j=\{a b c\}\right. \\
& \text { The restriction talk about above can be spoken as } \\
& S A j+S B j+S C j=1 \text { where } j=\{a b c\}
\end{aligned}
$$

With these limitations, the $3 \times 3$ matrix converter has 27 possible switching states

\section{MODULATION METHODOLOGIES}

\section{BASIC MODULATION TECHNIQUE}

For a 3x3 input voltages and output currents will have phase displacement of 120 . Modulation matrix $\mathrm{M}(\mathrm{t})$ will be obtained by to such an extent that the constraint equation is fulfilled.

The output and input voltages

$$
V_{o}=q V_{i m}\left[\begin{array}{l}
\cos \left(W_{o} t\right) \\
\cos \left(W_{o} t+2 * \pi / 3\right) \\
\cos \left(W_{o} t+4 * \pi / 3\right)
\end{array}\right]
$$

$$
i_{o}=q \cdot \cos (\phi o) I_{o m}\left[\begin{array}{l}
\cos \left(W_{i} t+\phi\right) \\
\cos \left(W_{i} t+\phi+2^{*} \pi / 3\right) \\
\cos \left(W_{i} t+\phi+4^{*} \pi / 3\right)
\end{array}\right]
$$

The essential answer for above,

$$
M=1 / 3 .\left[\begin{array}{ccc}
1+2 g \cdot \cos (\pi / t) & 1+2 q \cdot \cos \left(W_{t} t-2^{*} \pi / 3\right) & 1+2 g \cdot \cos \left(W_{t} t-4^{*} \pi / 3\right) \\
1+2 g \cos \left(\pi / t-4^{*} \pi / 3\right) & 1+2 g \cdot \cos \left(W_{t} t\right) & 1+2 g \cdot \cos \left(W_{t} t-2^{*} \pi / 3\right) \\
1+2 g \cdot \cos \left(\pi / t-2^{*} \pi / 3\right) & 1+2 g \cos \left(W_{t} t-4^{*} \pi / 3\right) & 1+2 g \cdot \cos (\pi / t)
\end{array}\right]
$$

The essential answer for above,

$$
\begin{aligned}
& 1+2 g \cdot \cos (\pi / t) \quad 1+2 g \cdot \cos (\pi / t-2 * \pi / 3) \quad 1+2 g \cdot \cos (W / t-4 * \pi / 3)] \\
& M=1 / 3.1+2 g \cdot \cos \left(\pi / t-4^{*} \pi / 3\right) \quad 1+2 g \cdot \cos (W / t) \quad 1+2 g \cdot \cos \left(W_{t} t-2^{*} \pi / 3\right) \\
& {[1+2 g \cos (\pi / t-2 * \pi / 3) 1+2 q \cos (\pi / 2 t-4 * \pi / 3) \quad 1+2 g \cos (\pi / t)]}
\end{aligned}
$$

The above arrangement yields $\phi=\phi_{o}$, giving a similar phase at the both sides, though the arrangement yields, $\phi=-\phi_{o}$ arrangements gives the means for control of input displacement factor.

The modulation arrangements gives a maximum voltage ratio (VR) (q) of $50 \%$ with a development in the VR to $\sqrt{3}$ 12 (or $87 \%$ ) is achievable by totaling common-mode voltages in the direction of objective outputs.

$$
\begin{gathered}
V_{o}=q \cdot V_{i m} \\
{\left[\begin{array}{c}
\cos \left(\omega_{o} t\right)-\frac{1}{6} \cos \left(3 \omega_{0} t\right)+\frac{1}{2 \sqrt{3}} \cos \left(3 \omega_{i} t\right) \\
\cos \left(\omega_{o} t+2 \pi / 3\right)-\frac{1}{6} \cos \left(3 \omega_{o} t\right)+\frac{1}{2 \sqrt{3}} \cos \left(3 \omega_{i} t\right) \\
\cos \left(\omega_{o} t+4 \pi / 3\right)-\frac{1}{6} \cos \left(3 \omega_{o} t\right)+\frac{1}{2 \sqrt{3}} \cos \left(3 \omega_{i} t\right)
\end{array}\right]}
\end{gathered}
$$

It has no impact on the line voltages, but permits the required outputs to robust surrounded by the input voltage envelope with a value of 'q' up to $87 \%$. It is similar to predictable dc-link PWM converters. Venturini provides a rigorous proof of this fact.

\section{VENTURINI-ALESINA MODULATION TECHNIQUE}

The switch timings straightforwardly actualized regarding the information of input and output voltages as stated above.

$$
M=1 / 3\left[1+\left(2 \times v \times v_{j}\right) / V^{2} i m\right]
$$

For $\mathrm{K}=\mathrm{A}, \mathrm{B}, \mathrm{C}$ and $\mathrm{j}=\mathrm{a}, \mathrm{b}, \mathrm{c}$.

This strategy is of little practical significance criticalness on account of the half VR confinement. Venturini's ideal strategy utilizes the common-mode addition method defined to obtain a maximum VR of $87 \%$. It can be expressed as 


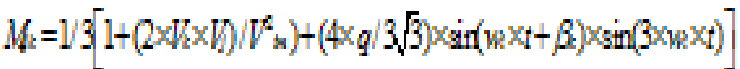 For $\mathrm{K}=\mathrm{A}, \mathrm{B}, \mathrm{C}$ and $\mathrm{j}=\mathrm{a}, \mathrm{b}, \mathrm{c}$. $\beta=0,2 \times \pi / 3,4 \times \pi / 3$, For $\mathrm{K}=\mathrm{A}, \mathrm{B}, \mathrm{C}$ respectively.}

The phase shift between the measured input voltages and the voltages $\mathrm{Vk}$ inserted will results in control of input displacement factor..

\section{SCALAR MODULATION TECHNIQUE}

It can be implemented where the switch actuation signals are premeditated from input voltages from the below procedure.

Step 1) Allocate subscript $M$ to the input which has a alternate polarity to the next two.

Step 2) Allocate subscript L to the smaller value of other two inputs. Where third is allocated subscript $\mathrm{K}$.

The duty cycles are obtained by

$\mathrm{MLj}=(\mathrm{Vj}-\mathrm{Vm}) . \mathrm{VL} /(1.5 \mathrm{~V} 2 \mathrm{im})$

$\mathrm{Mkj}=(\mathrm{Vj}-\mathrm{Vm}) . \mathrm{Vk} /(1.5 \mathrm{~V} 2 \mathrm{im})$

$\mathrm{Mmj}=1-(\mathrm{MLj}+\mathrm{Mkj}) \quad$ for $\mathrm{j}=\mathrm{a}, \mathrm{b}, \mathrm{c}$.

Once more, common-mode addition is used with the objective output Voltages $\mathrm{Vj}$ to accomplish $87 \% \mathrm{VR}$ capability. Duty cycles expressed as.

$$
\left.M_{j k}=1 / 3\left[1+\left(2 \times V_{k} \times V_{j}\right) / V^{2}{ }_{i m}\right)+2 / 3 \times \sin \left(w_{i} \times t+\beta_{k}\right) \times \sin \left(3 \times w_{i} \times t\right)\right]
$$

At low switching frequencies the output voltage quality is exception and both scalar and venturini are indistinguishable as the maximum output voltage $(q=\sqrt{3} / 2)$ remains same. Where the Venturini method is superior.

Space vector modulation technique

The SPVM is outstanding and set up in traditional conventional PWM inverters. Its application to this converter is thoughtfully the equivalent, but is more complex. The output voltage SPVM can be obtained and distinct in provisions of the line voltages.

$$
\begin{gathered}
\qquad \begin{array}{l}
V_{o}(t)=2 / 3\left(V_{a b}+a \times V_{b c}+a^{2} \times V_{c a}\right) \\
I_{i}(t)=2 / 3\left(I_{a}+a \times I_{b}+a^{2} \times I_{c}\right)
\end{array} \\
\text { Where } a=\exp (j \times 2 \times \pi / 3)
\end{gathered}
$$

Vector of fixed length ( $q$ Vim) rotates in the complex plan with at angular frequency W0. For a matrix converter, the details of each vectors in detail is given below. There are active vectors have in both direction $( \pm 1, \pm 2, \pm 3, \pm 4, \pm 5, \pm 6$, $\pm 7, \pm 8, \pm 9$ ),Zero vectors $0 \mathrm{a}, 0 \mathrm{~b}$ and $0 \mathrm{c}$ and rotating vectors are constant magnitude $( \pm 10, \pm 11, \pm 12)$. The below table demonstrates the 27 switching states corresponding to 27 vectors. direction depends on the angles $\alpha, \beta$

The 27 achievable yield vectors of $3-\varnothing$ matrix converter can be ranked into 3 groups by means of the subsequent characteristics

- Ist Group: constant amplitude space vectors output line

\begin{tabular}{|c|c|c|c|}
\hline rease & abs & Vo & $\beta_{i}$ \\
\hline-1 & $A B B$ & $0.667 V_{A z}$ & $2 / \sqrt{3}$ \\
\hline-1 & $B A A$ & $-0.667 V_{A z}$ & $-2 / \sqrt{3}$ \\
\hline-2 & $B C C$ & $0.667 V_{a c}$ & $2 / \sqrt{3}$ \\
\hline 2 & $C B B$ & $4.667 V_{s c}$ & $-2 / \sqrt{3}$ \\
\hline-3 & CAA & $0.667 \mathrm{Var}$ & $7 \times \pi / 6$ \\
\hline 3 & $A C C$ & $-6.667 \mathrm{Va}$ & $-2 / \sqrt{3}$ \\
\hline-4 & $\overline{B A B}$ & $0.667 V_{A z} \quad 2 \times \pi / 3$ & $2 / \sqrt{3}$ \\
\hline 4 & $\overline{A B A}$ & $0.667 V_{A z} \quad 2 \times \pi / 3$ & $-2 / \sqrt{3}$ \\
\hline-5 & CBC & $0.667 V_{x c} \quad 2 \times \pi / 3$ & $2 / \sqrt{3}$ \\
\hline-5 & $\overline{B C B}$ & $0.667 V_{x}=2 \times \pi / 3$ & $-\pi / 2$ \\
\hline-6 & $\overline{A C A}$ & $0.667 \mathrm{Va} \quad 2 \times \pi / 3$ & $7 \times \pi / 6$ \\
\hline 4 & CAC & 0.667 Var $\quad 2 \times \pi / 3$ & $7 \times \pi / 6$ \\
\hline 4 & $A A B$ & $0.667 V_{i s} \quad 4 \times \pi / 3$ & $2 / \sqrt{3}$ \\
\hline 4 & AAB & $4.667 V_{i z} \quad 4 \times \pi / 3$ & $2 / \sqrt{3}$ \\
\hline-3 & $C C B$ & $0.667 V x c \quad 4 \times \pi / 3$ & $2 / \sqrt{3}$ \\
\hline-4 & B B C & $0.667 V_{x c} \quad 4 \times \pi / 3$ & $-2 / \sqrt{3}$ \\
\hline 4 & AAC & 0.667 Va $\quad 4 \times \pi / 3$ & $7 \times \pi / 6$ \\
\hline 9 & $C C A$ & $-0.667 V a \quad 4 \times \pi / 3$ & $2 / \sqrt{3}$ \\
\hline$\frac{\mathrm{Oa}}{\mathrm{O} b}$ & $\begin{array}{ll}\text { AA A } \\
\text { B B B }\end{array}$ & $\frac{0}{0}$ & 0 \\
\hline$\alpha e$ & $\mathrm{ccc}$ & 0 & 0 \\
\hline-10 & $A B C$ & $\alpha_{s}+0$ & $\beta+0$ \\
\hline-10 & $\overline{A C B}$ & $-\alpha_{r}+0$ & $I_{a=x:} \quad-\beta_{i}-0$ \\
\hline-11 & CAB & $V_{t=1 x} \alpha_{N}+(2 \times \pi / 3)$ & $I_{a=x:} \quad \beta_{t}+2 \times \pi / 3$ \\
\hline-11 & BAC & $V_{t=1 x}-\alpha_{I}-(2 \times \pi / 3)$ & $I_{a=x:}-\beta_{i}-2 \times \pi / 3$ \\
\hline-12 & $B C A$ & $V_{t=1 x} \alpha_{N}+(4 \times \pi / 3)$ & $I_{a=x} \quad \beta_{t}+4 \times \pi / 3$ \\
\hline-12 & $C B A$ & $V_{t=1 x}-\alpha_{I}-(4 \times \pi / 3)$ & $I_{a=x}-\beta_{u}-4 \times \pi / 3$ \\
\hline
\end{tabular}
be linked with a dissimilar input line with supply angular frequency.
Table 1. SPACE VECTORS

- Ind Group: at common input line 2 output lines be connected. At other input lines the left over output lines are connected. The highest length of space vectors is $2 / \sqrt{3}$ Venv where Venv is the instant value of the rectified input voltage with phase spread of 600 envelope.

- IIIrd Group: at common input line each and every one output lines are coupled. At origin Output space vectors have zero amplitude.

once more IInd group again sub-divided into 3 groups as extend in Fig.

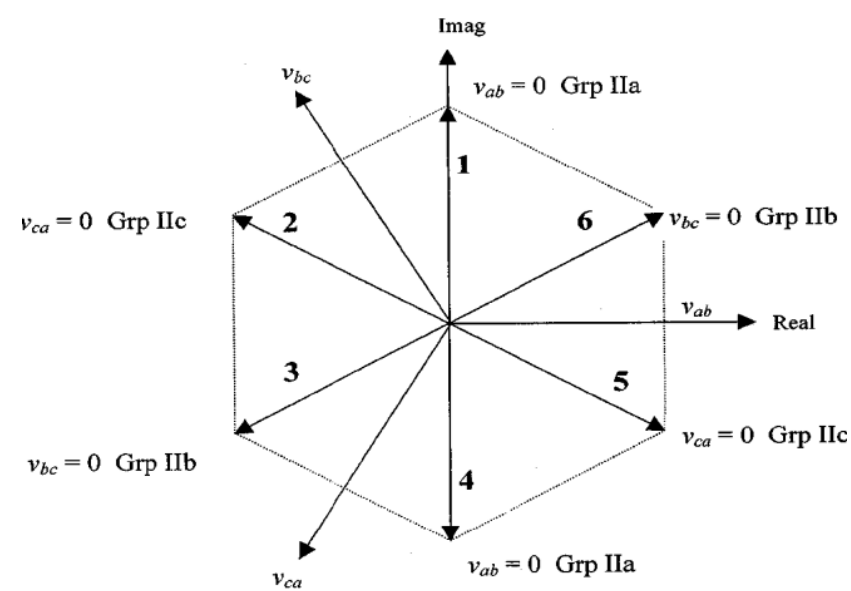

Figure 4. Output voltage space vectors. 
In the SPVM, the Ist Group vectors be not utilized. The ideal output is amalgamated with active and zero vectors. The output vectors in hexagon are represented. Where the active vectors are additionally separated reliant on which zero line output voltage.

$\mathrm{Vo}(\mathrm{t})$ is produced during time averaging by prefer the time between vector 1 and $6(\mathrm{t} 1) \&(\mathrm{t} 2)$ during sequence of switching. at this time, it is accepted that the highest length vectors are used, despite the fact that does not need to be the situation.

$$
\begin{aligned}
& t_{1}=\left(\left|V_{0}\right| / V_{\text {env }}\right) \times T_{\text {seq }} \times \sin (\theta), \\
& t_{6}=\left(\left|V_{0}\right| / V_{\text {env }}\right) \times T_{\text {seq }} \times \sin (60-\theta), \\
& t_{0}=T_{\text {seq }}-\left(t_{1}+t_{6}\right)
\end{aligned}
$$

Time spent at zero vector is $t 0$. There will be no exclusive way for allocate the times ( $t 1, t 6, t 0)$ contained by the switching arrangement. It is important to apply the SPVM to input current control and output voltage control for good harmonic performance. Here 4 active vectors are required each switching case. Which give same results but here the number of switching vectors selection is more flexible.

\section{INDIRECT MODULATION TECHNIQUES}

These strategies intend to expand the methods intend to amplify the higher VR beyond the $86.6 \%$ furthest reaches of different techniques. For this, the process is to be splitted into two stages as indicated. $\mathrm{Vo}=(\mathrm{A} . \mathrm{Vi}) . \mathrm{B}$

In above equation, the input voltages from rectifier transformation (a) Generates a "fictitious dc link" and inverter transformation (b) Generates a preferred output by modulating the "fictitious dc link."

$$
\mathbf{A}=K_{A}\left[\begin{array}{c}
\cos \left(\omega_{i} t\right) \\
\cos \left(\omega_{i} t+2 \pi / 3\right) \\
\cos \left(\omega_{i} t+4 \pi / 3\right)
\end{array}\right]^{T}
$$

Here,

$$
\begin{gathered}
\mathbf{A} \mathbf{v}_{\mathrm{i}}=K_{A} V_{i m}\left[\begin{array}{c}
\cos \left(\omega_{i} t\right) \\
\cos \left(\omega_{i} t+2 \pi / 3\right) \\
\cos \left(\omega_{i} t+4 \pi / 3\right)
\end{array}\right]^{T}\left[\begin{array}{c}
\cos \left(\omega_{i} t\right) \\
\cos \left(\omega_{i} t+2 \pi / 3\right) \\
\cos \left(\omega_{i} t+4 \pi / 3\right)
\end{array}\right] \\
A \cdot v_{i}=\left(3 \times K_{A} \times V_{i m)} / 2\right. \\
\mathbf{B}=K_{B}\left[\begin{array}{c}
\cos \left(\omega_{o} t\right) \\
\cos \left(\omega_{o} t+2 \pi / 3\right) \\
\cos \left(\omega_{o} t+4 \pi / 3\right)
\end{array}\right] .
\end{gathered}
$$

Hence,

$$
\mathbf{v}_{o}=\left(\mathbf{A} \mathbf{v}_{\mathbf{i}}\right) \mathbf{B}=\frac{3 K_{A} K_{B} V_{i m}}{2}\left[\begin{array}{c}
\cos \left(\omega_{o} t\right) \\
\cos \left(\omega_{o} t+2 \pi / 3\right) \\
\cos \left(\omega_{o} t+4 \pi / 3\right)
\end{array}\right] .
$$

The VR $q=3 \times K_{A} \times K_{B} / 2$. From the above exhibits undoubtedly, the $\mathrm{A}$ and $\mathrm{B}$ modulation steps are discontinuous, To maximize the VR, the most positive and negative input voltages are selected continuously to produce step A. This yields $\mathrm{K}_{\mathrm{A}}=2 / \sqrt{3} / \pi$ with a "fictitious de link" of $3 \sqrt{3} \mathrm{Vim} / \pi$ represents the MI of a PWM process and has the peak value of. The overall VR therefore has the peak value of $6 \sqrt{3} / \pi^{2}=105.3 \%$. The VR available is more than that of other techniques but the improvement is only obtained at the expense of the quality of either the input currents, the output voltages or both. For values of $q>0.866$, the mean output voltage no longer equals the target output voltage.

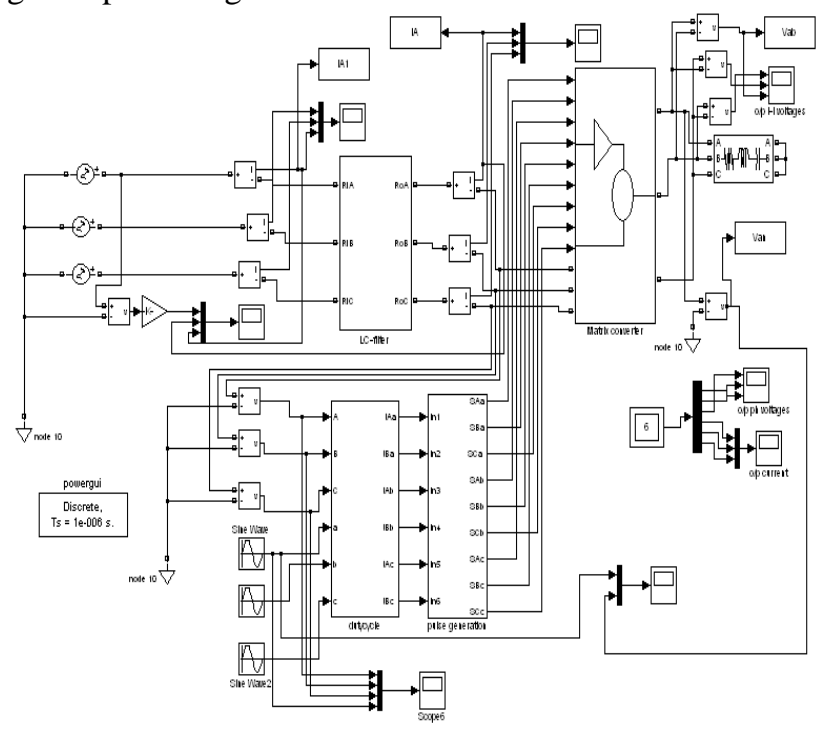

Figure 5 Complete block diagram of Venturini modulation strategy.

In this method $\mathrm{q}$ is directly taken as $\sqrt{3} / 2$.

Hence,

$$
\left.M_{j k}=1 / 3\left[1+\left(2 \times V_{k} \times V_{j}\right) / V^{2}{ }_{i m}\right)+2 / 3 \times \sin \left(w_{i} \times t+\beta_{k}\right) \times \sin \left(3 \times w_{i} \times t\right)\right]
$$

Space vector modulation technique method

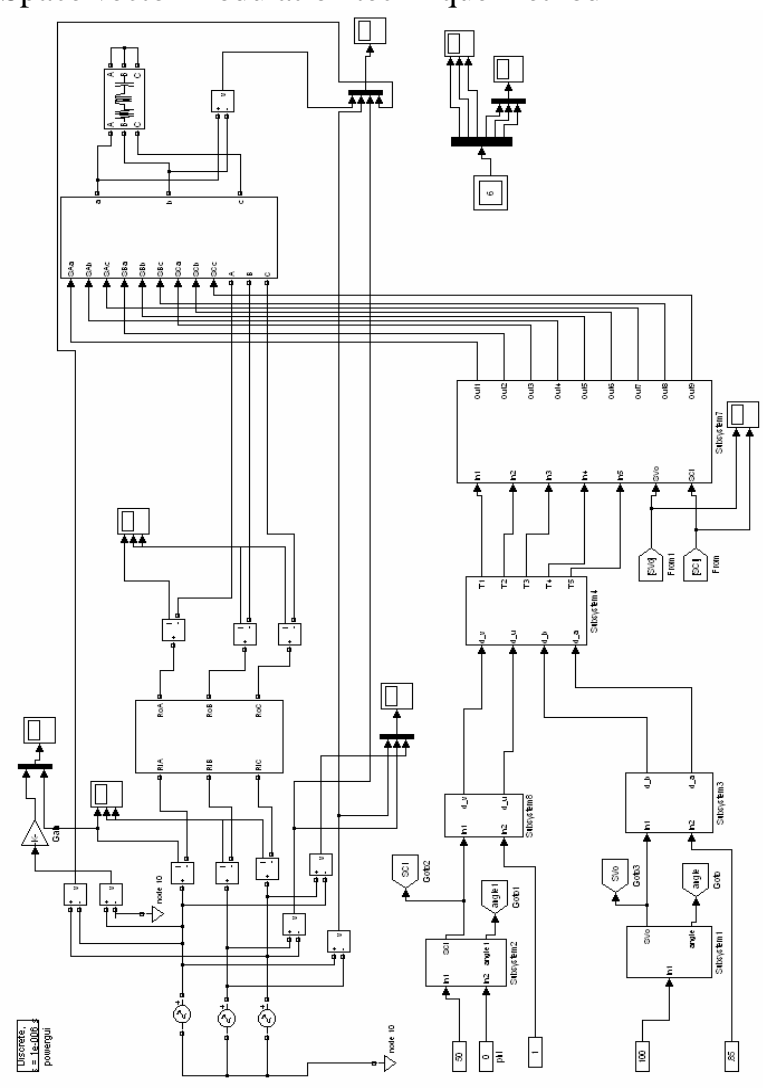

Figure 6 SVM complete block Representation.

Published By:

Blue Eyes Intelligence Engineering

\& Sciences Publication 
From input current and required output voltage switching strategies of SVM are obtained. For sector identification and to find out the current angle Sci. Each sector is of 60 degrees and starts from $-30<$ sector $1<30$. To get 360 degrees rotation and to start from 0 after every cycle. For division of 360 degrees into 6 sectors and identification of sectors, Conversion of Sci into degrees and applying sin gives $d \_u$ and d_v respectively. Sci is divide into 0 to $60 \mathrm{deg}$ from out 1 , 60 to 0 from out 2 .

\section{SIMULATION RESULTS}

Basic modulation technique OUTPUT voltage wave form Vim=400; Ii=200A; Fi=50; Qi=0;---input.

$\mathrm{Fo}=100 ; \mathrm{Qo}=30 ; \mathrm{q}=0.5 ; \mathrm{Vo}=200$.---output.

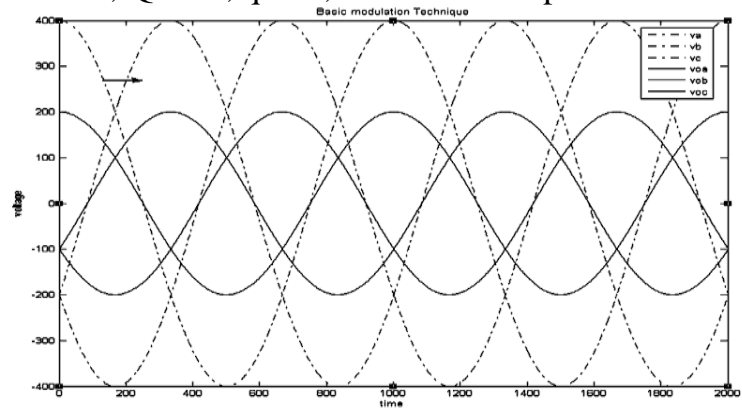

Fig.7.output voltage and current for basic modulation technique.

The dotted lines are input voltages $\mathrm{VA}, \mathrm{VB}, \mathrm{VC}$ and thick lines are the output voltages $\mathrm{Va}, \mathrm{Vb}, \mathrm{Vc}$.

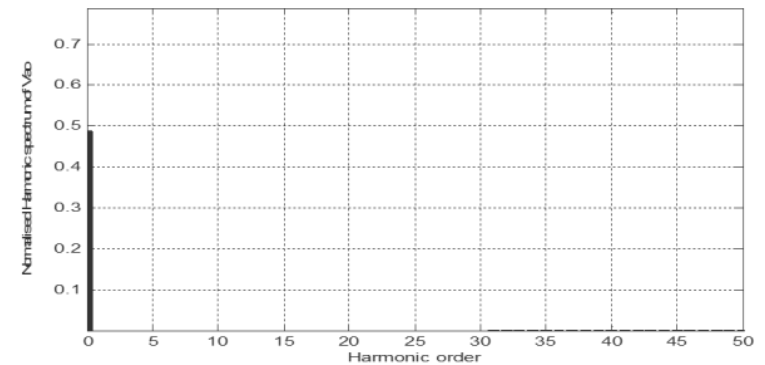

Fig.8Fundamental Harmonic

For different voltage and frequency.

Vim=400v; Ii=200A; Fi=50; Qi=0;

$\mathrm{Fo}=40 ; \mathrm{Qo}=30 ; \mathrm{q}=0.4 ; \mathrm{Vo}=160 \mathrm{v}$

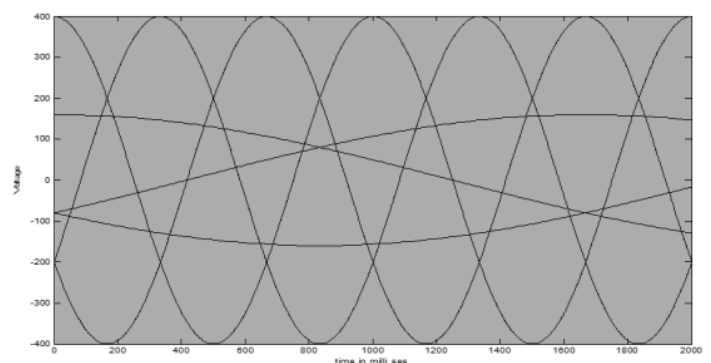

Fig.9 output voltage and current for basic modulation technique.

Alesina -Venturini modulation technique OUPUT WAVE FORMS

\footnotetext{
Vim $=220 \times \sqrt{2} \mathrm{v}, \mathrm{Fi}=50 \mathrm{~Hz},-------$ input

$\mathrm{Vom}=250 \mathrm{v}, \mathrm{Fo}=50 \mathrm{~Hz}$
}

Ub1: Three-Phase Series RLC Branch

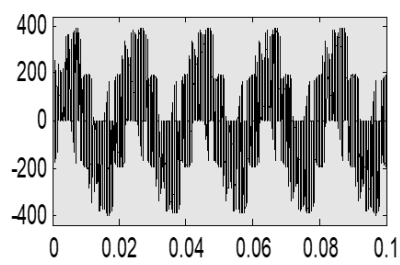

Ub3: Three-Phase Series RLC Branch
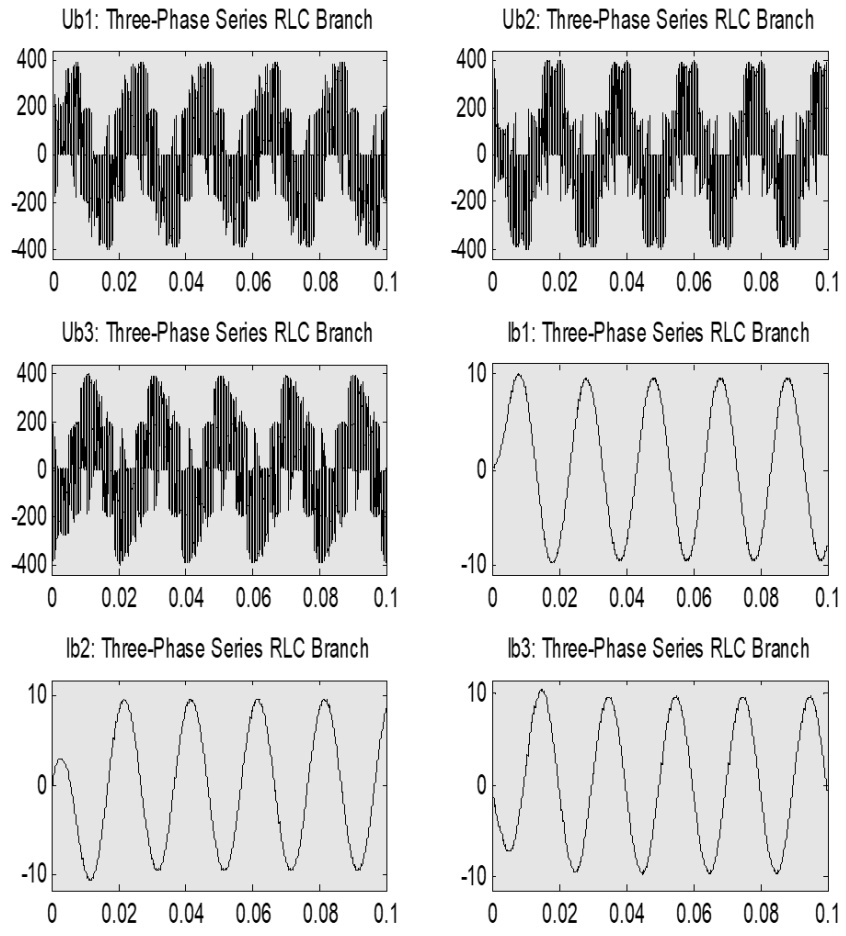

b1: Three-Phase Series RLC Branch

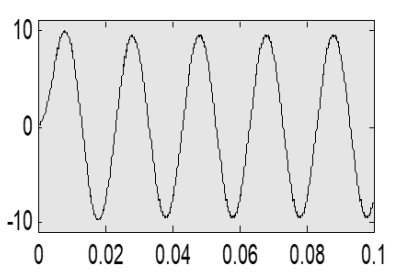

b3: Three-Phase Series RLC Branch

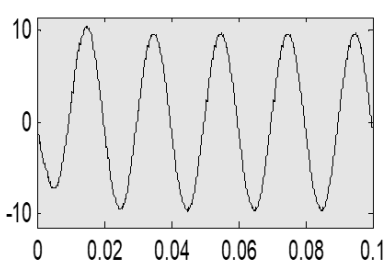

Figure 10 Output Voltage and Current of Alesina-Venturini Strategy.

Output for different output voltage and frequency as shown in Fig.below.

Vim $=220 \mathrm{v}, \mathrm{Fi}=50 \mathrm{~Hz},--------i n p u t$

$\mathrm{Vom}=250 \mathrm{v}, \mathrm{Fo}=50 \mathrm{~Hz}$
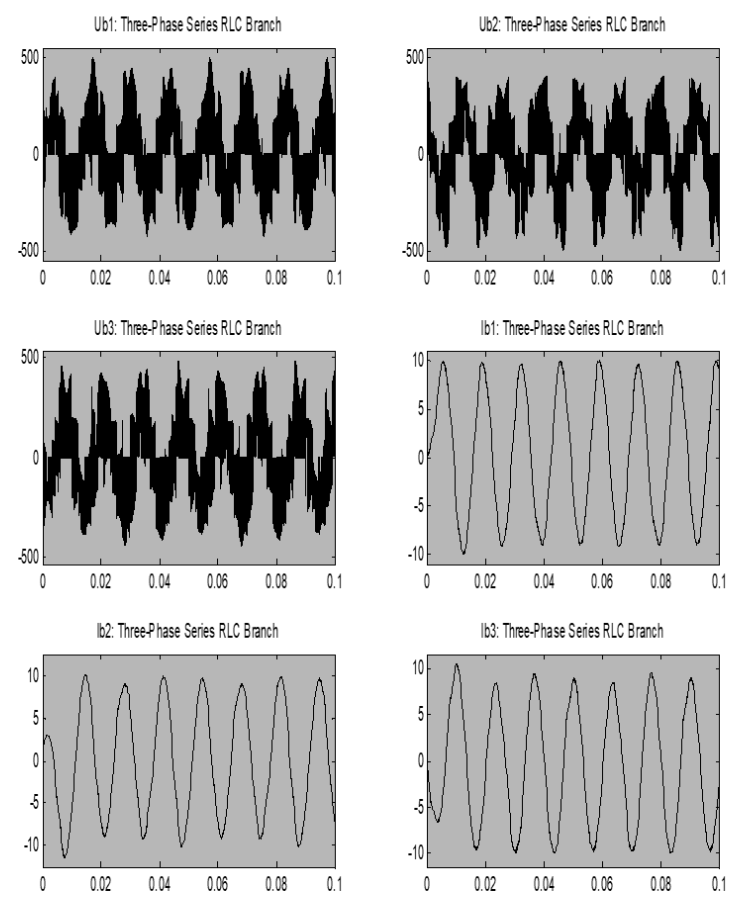

Figure.11. Output Voltage and Current of Venturini Strategy. 
Scalar modulation technique OUTPUT WAVE FORM

$\mathrm{Vim}=220 \mathrm{v}, \mathrm{Fi}=50 \mathrm{~Hz},--------$ input

$\mathrm{Vom}=155.56 \mathrm{v}, \mathrm{Fo}=100 \mathrm{~Hz}$ Ub1: Three-Phase Series RLC Branch

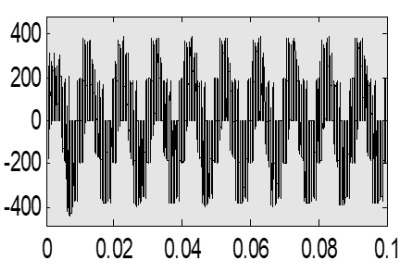

Ub3: Three-Phase Series RLC Branch

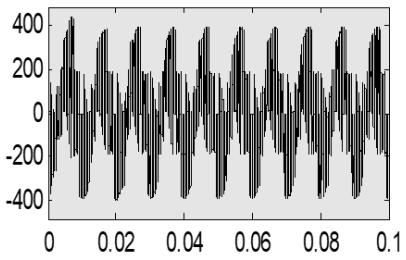

Ib2: Three-Phase Series RLC Branch

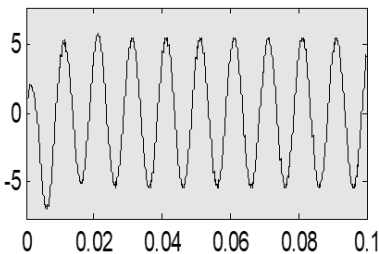

\section{-output}

Ub2: Three-Phase Series RLC Branch

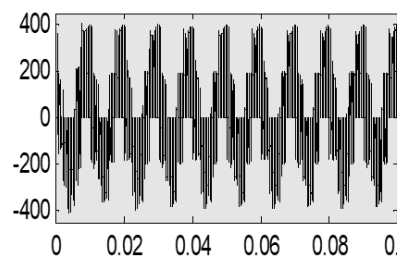

Ib1: Three-Phase Series RLC Branch

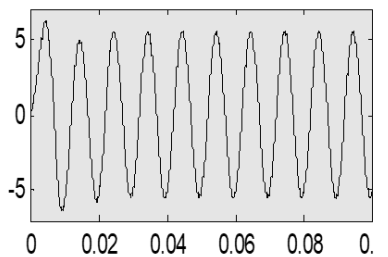

lb3: Three-Phase Series RLC Branch

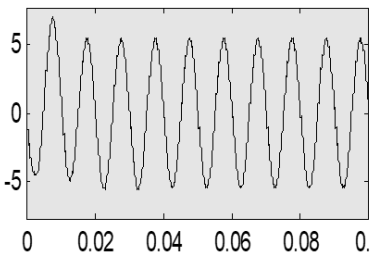

$\begin{array}{llllll}0 & 0.02 & 0.04 & 0.06 & 0.08 & 0\end{array}$

Figure 12 Output Voltage and Current of Scalar Method.

Space vector modulation technique OUPUT WAVEFORM

$\mathrm{Vim}=220 \mathrm{v}, \mathrm{Fi}=50 \mathrm{~Hz}$,

Vom $=250 \mathrm{v}, \mathrm{Fo}=50 \mathrm{~Hz}, \mathrm{Qo}=0.85$ -input

Ub1: Three Phase Series RLC Branch

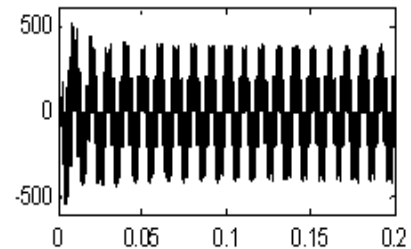

Ut2: Three.Phase Series RLC Branch

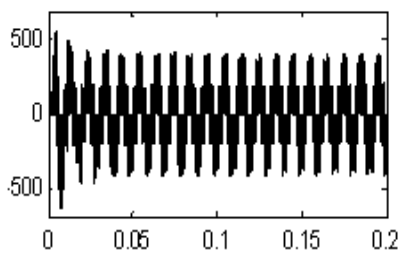

Utb: Three-Phas Series RLC Branch

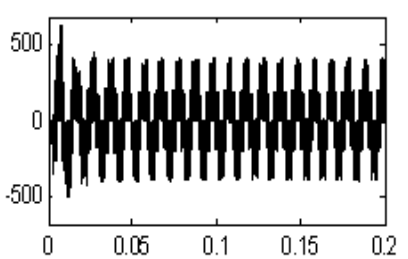

Ubt: There-Phose Series Rlc: Brach

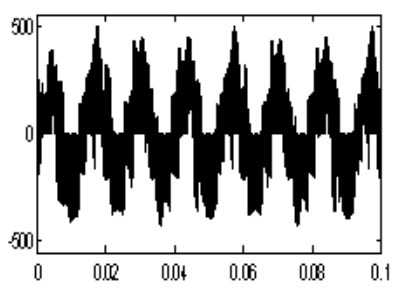

IVb2: Thee-Phase Series Alc: Branch

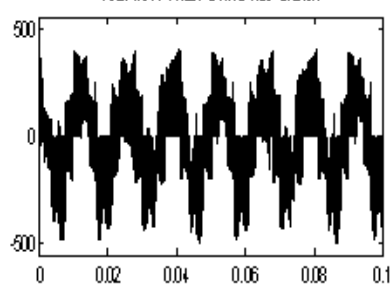

Ub3: Tree-Phase Senies Alc Brand

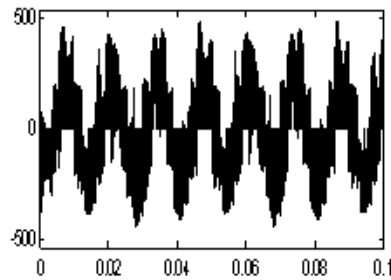

b1: Theep-Phose Senies FlC Branch

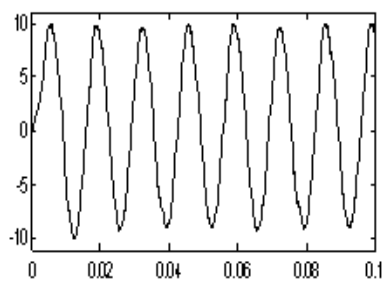

b2: Thee-Phase Senes PlC. Branch

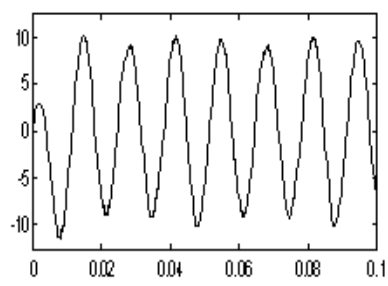

b3: Thee-Phase Senes Rlc Brach

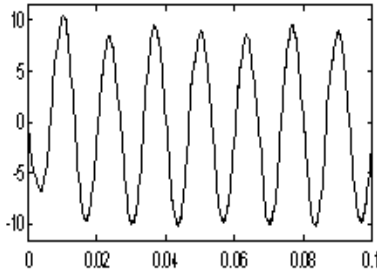

Figure.14. Output Voltage and Current of SVM strategy

Following are Outputs for different output voltage and frequency as shown in Fig. above.

$\mathrm{Vim}=220 \times \sqrt{2} \mathrm{v}, \mathrm{Fi}=50 \mathrm{~Hz}$,

Vom $=160 \mathrm{v}, \mathrm{Fo}=100 \mathrm{~Hz}, \mathrm{Q}=.60$

--------input

Relation of Basic, Venturini \& SVM techniques

In the SVM strategy, there are 3 zero arrangements utilized to finish the switching cycle. Various ways be present to place and distribute zero vectors. Various circulations yield diverse SVM strategy. Usually, indistinguishable duty-cycles are distributed symmetrically in every switching cycle.

In present paper, the unbalanced distribution will exist actualized and duty-cycles of 3 zero arrangements will be determined to set up the identical SVM technique to the basic/ideal AV strategy. The different AV strategies are, the strategy without and with the common mode injection sort from $50 \%$ to $86 \%$ analogous to every method.

Following two many years of research exertion, a few modulation and control techniques have been created for the matrix converter, for the induction of sinusoidal input and output currents, with power factor as one (UPF).

The most significant practical execution issue in the matrix converter circuit is the commutation of switches, has been resolved with the expansion of highly knowledgeable multistep commutation methodologies. Power modules overcome this limitation with the help of matrix converter. Anyhow, research result has demonstrated that this converter is not a "pure silicon converter" and input filters are needed to that of passive elements. More work must be done so as to upgrade the size of these filters.

As long ago, performance point of view the matrix converter could be a predominant converter. Now, this

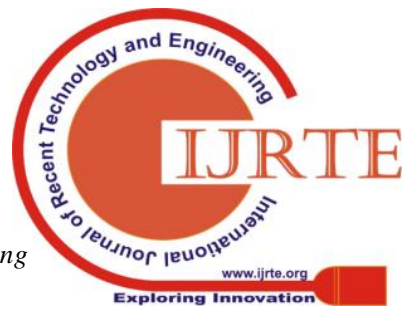


converter faces an extremely solid challenge from the VSI with $3-\varnothing$ active front end (AFE).

This VSI-AFE method is similar to matrix converter on the basis of operating characteristics but must overcome in requisites of expenses, size, and dependability.

\section{CONCLUSION}

This paper audits some outstanding modulation methods ideal AV strategy and space vector technique. Two SVM methodologies are accounted in literature, indirect and direct SVM. Simulation for Basic, Alesina-Venturini, Scalar modulation techniques is done and also Space vector modulation technique simulation has been done for direct modulation method. In theory both strategies are equal.

The duty-cycle of every switch can be characterized by mix of space vectors. The repeal of the conversion is also recognized. Unlike the SVM, which conveys zero vector analogously, with unequal intervals 3 zero contour are used.

This paper additionally researches the intrinsic affinity between the combined SVM technique and the AV stratagy. input UPF is assumption. The AV strategy is characterized in time domain, and the SVM is characterized by space vectors in the complex space.

\section{REFERENCES}

1. School of Electrical and Electronic Engineering University Park Nottingham, NG72RD" Matrix Converters: A Technology Review" IEEE TRANSACTIONS ON INDUSTRIAL ELECTRONICS, VOL. 49, NO. 2, APRIL 2002

2. Fang Gao, Student Member, and M. Reza Iravani, Fellow, "Dynamic Model of a Space Vector Modulated Matrix Converter" IEEE TRANSACTIONS ON POWER DELIVERY, VOL. 22, NO. 3, JULY 2007.

3. C Watthanasam, L Zhang, D T W Liang "Analysis and DSP-based Implementation of a Modulation Algorithms for AC-AC Matrix Converters "Dept. of Electronic and, Electrical Engineering University of Bradford, Bradford, BD7 IDP, UK

4. Hong-Hee Lee, Hoang M. Nguyen, Eui-Heon Jung," A Study on Reduction of Common-Mode Voltage in Matrix Converter with Unity Input Power Factor and Sinusoidal Input/Output Waveforms." School of Electrical Engineering University of Ulsan Muger2Dong Nam-gu, Ulsan city Republic of Korea.

5. Fan Yue, Patrick W. Wheeler, and Jon C. Clare,"Relationship of Modulation Schemes for Matrix Converters" School of Electrical \& Electronic Engineering University of Nottingham, University Park Nottingham,

6. Huber, BorojeviC," Space Vector Modulated Three-phase to Three- phase Matrix Converter with Input Power Factor Correction" IEEE TRANSACTIONS ON INDUSTRY APPLICATIONS, VOL. 31, NO 6, NOV/DEC 1995

7. M. Venturini, "A new sine wave in sine wave out, conversion technique which eliminates reactive elements," in Proc. POWERCON 7, 1980, pp.E3_1-E3_15.

8. Domenico Casadei, Senior Member, IEEE, Giovanni Serra, Senior Member, IEEE Angelo Tani, Andrew Trentin, and Luca Zarri" Theoretical and Experimental Investigation on the Stability of Matrix Converters" IEEE TRANSACTIONS ON INDUSTRIAL ELECTRONICS, VOL. 52, NO. 5, OCTOBER 2005. 